\title{
Corrigenda
}

\section{MiR-181 mediates cell differentiation by interrupting the Lin28 and let-7 feedback circuit}

\author{
X Li, J Zhang, L Gao, S McClellan, MA Finan, TW Butler, LB Owen, GA Piazza and Y Xi
}

Cell Death and Differentiation (2012) 19, 551; doi:10.1038/cdd.2011.199

Correction to: Cell Death and Differentiation (2012) 19, 378-386; doi:10.1038/cdd.2011.127; published online 7 October 2011

Since the publication of this article, the authors above have noticed that the column graphs of Figure $6 e$ and $f$ were incorrect in its online version.
This error has now been rectified, and the correct article appears in this issue. The html and online pdf versions have also been rectified, and now carry the correct paper.

The authors apologize for any inconvenience caused.

\section{Bcl-2 induces pro-oxidant state by engaging mitochondrial respiration in tumor cells}

\author{
ZX Chen and S Pervaiz
}

Cell Death and Differentiation (2012) 19, 551; doi:10.1038/cdd.2011.187

Correction to: Cell Death and Differentiation (2007) 14:1617-1627; doi:10.1038/sj.cdd.4402165

In Figure S1b of the Supplementary Figures, the wrong actin blot was used as a loading control, which did not correlate with the particular set of experiment performed. This has been corrected and replaced with the appropriate actin blot correlating to this particular set of experiment in Figure S1b. The findings and conclusion derived from Figure $S 1 \mathrm{~b}$ remains unchanged.

The correct Supplementary Figure is shown below. The authors would like to apologize for the oversight and any inconvenience it might have caused.

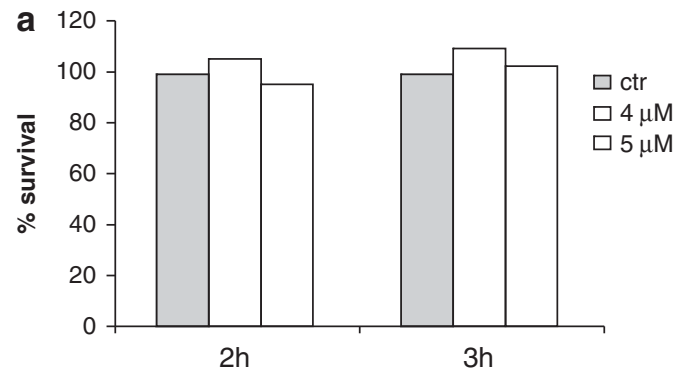

b

Bcl-2

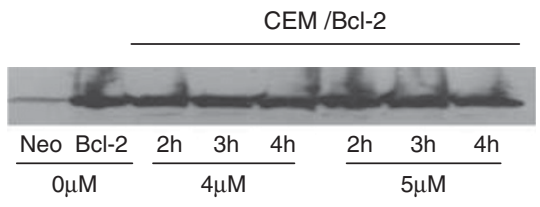

$\beta$-actin 